\title{
Hücre-dışı Fetal DNA'dan Gerçek-zamanlı PZR ile Fetal Rhesus D Tespitinin Maliyet Değerlendirmesi
}

\author{
Cost Evaluation of Fetal Rhesus D Genotyping by Real-time PCR from cell-free \\ Fetal DNA
}

\author{
Büşra Yaşa ${ }^{1,2}$ (D), Orhan Şahin³ ${ }^{\text {(D) }}$, Selçuk Sözer Tokdemir ${ }^{1}$ (D) \\ IIstanbul Üniversitesi, Aziz Sancar Deneysel Tıp Araștırma Enstitüsü, Genetik Anabilim Dalı, İstanbul, Türkiye \\ ${ }^{2}$ Istanbul Üniversitesi Sağlık Bilimleri Enstitüsü, Genetik Doktora Programı, İstanbul, Türkiye \\ ${ }^{3}$ Sağlık Bilimleri Üniversitesi, Okmeydanı Eğitim ve Araştırma Hastanesi, Kadın Hastalıkları ve Doğum Anabilim Dalı, İstanbul, Türkiye
}

ORCID ID: B.Y. 0000-0002-4967-6699; O.Ş. 0000-0002-7216-3816; S.S.T. 0000-0002-5035-4048

Cite this article as: Yaşa B, Şahin O, Tokdemir SS. Hücre-dışı fetal DNA'dan gerçek-zamanlı PZR ile fetal rhesus D tespitinin maliyet değerlendirmesi. Experimed 2020; 10(3): 124-7.

öz

Maternal plazmadan hücre-dışı fetal DNA'nın (hdfDNA) tespitinde son yıllarda elde edilen başarılar, hamilelik süresince uygulanabilir, invazif olmayan tarama ve tanı testlerini destekleyen temel tekniklerin gelişmesine olanak sağlamıştır. Yakın zamanda yaptığımız bir çalışmada, invazif işlem gerektirmeden gebelerden alınan periferik kandan hücre-dışı DNA izole edilerek, gerçek zamanlı polimeraz zincir reaksiyonu (PZR) yöntemiyle fetal Rhesus $D(R h D)$ ve cinsiyet belirlenmesi gerçekleştirilmiştir. Bu ve benzeri çalışmalar neticesinde, kullanılan tekniğin fetal RhD tayininde yüksek doğruluk oranlarına sahip olduğu ve tanı amaçlı kullanıma uygun olduğu gösterilmiştir. Tanıda elde edilen bu başarı, özellikle RhD negatif (-) gebelere uygulanan işlemleri en aza indirilerek tedavide yol göstericidir. Bu bağlamda, sunduğumuz bu çalışmada Türkiye Cumhuriyeti, Sosyal Güvenlik Kurumu, Sağlık Uygulama Tebliği (SUT) verileri referans alınarak, günümüzde $\mathrm{RhD}(-)$ gebelere uygulanan ek izlem testlerin ve tedavinin oluşturduğu maliyet ile fetal $R H D$ genotiplemesi sonucu ortaya çıkan maliyetin kıyaslaması gerçekleştirilmiştir. Ayrıca, böyle bir yaklaşımın hastalık tanı sürecine yapmış olduğu destek değerlendirilmiştir.

Sonuç olarak, her RhD (-) gebe için, gerçek zamanlı PZR uygulanarak fetal $R H D$ genotiplesi ile hali hazırda kullanılan ek tetkik ve tedaviler kıyaslandığında, 523,19 TL (3,5 kat) daha az maliyetli olduğu gösterilmiştir. Bu testin, iş yoğunluğu, hastane maliyetleri ve hastaya uygulanan gereksiz tedavilerin azalması yönünde yenilikçi bir yöntem olduğu görülmektedir. Ayrıca, bu ve benzeri yaklaşımlar, erken tedavinin başlatılması ve gereksiz müdahale ve maliyetten kaçınılmasına olanak sağlayacaktır.

Anahtar Kelimeler: Hücre dışı fetal DNA, RHD, genotipleme, maliyet analizi

\section{ABSTRACT}

The detection of cell-free fetal DNA (cffDNA) from maternal plasma has enabled the development of essential prenatal diagnostic techniques supporting the non-invasive screening and diagnostic tests in recent years.

We performed a non-invasive real-time polymerase chain reaction (PCR) using cell-free DNA isolated from the peripheral blood of pregnant women to determine fetal Rhesus $D(R h D)$ and sex. Consistent with the findings of similar studies, our results revealed high accuracy rates of PCR in determining fetal RhD, making it suitable for diagnostic use, thereby indicating its effectiveness as a guide in treating and especially in minimizing the procedures applied to pregnant women who are RhD negative.

This study compared the cost incurred between follow-up testing and treatment of $\mathrm{RhD}(-)$ pregnant women and the fetal RHD genotyping based on Health Implementation Notification (SUT) data of the Social Security Administration of the Republic of Turkey. Additionally, the role of PCR to the diagnostic process was evaluated.

Our results showed that fetal RHD genotyping costs 523.19 TL (3.5 times) less for each $\mathrm{RhD}(-)$ pregnant women compared with the current additional tests and treatments. PCR with cffDNA is an innovative method that minimizes workload, hospital costs, and unnecessary tests and treatment. In addition, this method allows an early initiation of treatment and avoidance of unnecessary intervention and cost.

Keywords: Fetal cell-free DNA, $R H D$, genotyping, cost analysis 


\section{GíRiş}

Eritroblastosis Fetalis, gebelerde annenin Rhesus (Rh) faktör negatif (-), fetüsün ise Rh pozitif (+) olduğu durumlarda gerçekleşir. Fetal eritrositler anne dolaşımında belli bir oranın üzerinde bulunduğunda, RhD antijenine karşı oluşan maternal lgG antikorlar, fetüse geçerek Rhesus hemolitik hastalığınına neden olur. Bu durum, fetüs için yüksek morbidite ve mortalite oluşturur (1). Fetal hemolizin önlenmesi için, anti-RhD immünoglobulin ile prenatal ve postnatal profilaksinin rutin kullanımı, RhD (-) kadınların alloimmünizasyonunu önemli ölçüde azaltmaktadır (2-4). RhD genotipinin prenatal dönemde tespiti, Rhesus hemolitik hastalığının erken dönemde belirlenmesinde önemli bir yer tutmaktadır (5). Son on yıllık dönemde doğum öncesi RhD (+) fetüsün belirlenmesi amacıyla oluşturulmuş olan farklı stratejilerde önemli ilerlemeler görülmüştür. Lo ve arkadaşları tarafından 1997'de gebe plazmasında keşfedilen hücre-dışı fetal DNA (hdfDNA) ile RhD'nin prenatal dönemde belirlenmesi anti-D profilaksisine ihtiyaç duyulmayan fetüslerin invaziv olmayan yöntemle tespiti için kullanılmıştır $(6,7)$. 2016'da yapılan geniş çapta bir metaanaliz çalışmasında, RHD genotiplemesinin tanısal doğruluğu ve klinik etkililiği gösterilmiştir. Bu çalışma sonucu $R H D$ genotiplemesi için \%0,34 yanlış negatif oran ve \%3,86 yanlış pozitif oran tespit edilmiştir. Bu ve benzeri sonuçlar neticesinde artık birçok ülkede, maternal plazma veya serumdan, dolaşımdaki hdfDNA'yı kullanarak fetal RhD durum tespiti rutin olarak kullanılmaktadır (8,9). Ayrıca erken tanı anti-D kullanılmasında hassas davranılmasını da sağlayacaktır (10).

Yakın zamanda yaptığımız bir çalışmada invaziv olmayan yöntem ile maternal kandan elde edilen hdfDNA ve hatta eksozom ile gerçek-zamanlı PZR yöntemi kullanarak fetal $R H D$ ve $S R Y$ genotiplemesinin başarılı olduğu gösterildi. Bu yöntemin her hasta için uygulanabilir ve güvenilir olduğu tarafımızdan tespit edildi (11). Ülkemizde, prenatal tanıda kullanılan yöntemler sırasında karşılaşılan tanı zorluğu ve bu kaotik süreçte hastaya yansıyan maddi ve manevi zorluklar dikkati çekmektedir.

Bu çalışmada, fetüsün $\mathrm{RhD}(+)$ olma şüphesiyle hemen hemen her RhD (-) gebeye uygulanan ek testler ve tedavinin hastaya yansıyan maddi yönü ile gerçek zamanlı PZR tekniği ile fetal RHD genotiplemesi yapılmasının maliyet analizini gerçekleştirildi. Uygulanılan bu yöntem, yaklaşık 3,5 kat daha az bir maliyet ile RhD uyuşmazlığının tanıdaki başarısını arttırmakta ve gereksiz proflaksi uygulanmasının önüne geçilebilmektedir.

\section{GEREÇ VE YÖNTEM}

\section{Örneklerin Toplanması ve Hücre Dışı Fetal DNA İzolasyonu Gerçek Zamanlı PZR Analizi ve Değerlendirmesi}

Bu çalışma İstanbul Üniversitesi, Aziz Sancar Deneysel Tıp Araştırma Enstitüsü, Genetik Anabilim Dalı'nda gerçekleştirilmiştir. Yapılan çalışma İstanbul Üniversitesi Tıp Fakültesi Klinik Araştırmalar Etik Kurulu'ndan 08.12.2017 tarihli 20 no'lu toplantısındaki onay ile başlamıştır ve İstanbul Üniversitesi Bilimsel Araştırma Projeleri 29083 nolu proje ile desteklenmiştir. Bu retrospektif çalışmaya, Sağlık Bilimleri Üniversitesi Okmeydanı Eğitim ve
Araştırma Hastanesi'nin Kadın Hastalıkları ve Doğum Kliniğine başvuran, RhD uyuşmazlığı bulunup gebelik haftası 9 ila 40 hafta arası olan $\mathrm{RhD}(-)$ gönüllü gebeler, onam formu alınarak dâhil edilmiştir. Gerçekleştirilen hücre-dışı DNA izolasyon ve gerçek zamanlı PZR protokolleri önceki çalışmamızda açıklanmıştır (11).

\section{Maaliyet Analizi}

Türkiye Cumhuriyeti, Sosyal Güvenlik Kurumunun, devlet hastaneleri için kullandığı ücretlendirme sistemi Sağlık Uygulama Tebliği (SUT 2020) verileri referans alınarak maaliyet ve ekonomik değerlendirme yapılmıştır. SUT verilerine göre RhD (-) gebelere yapılan ek test kodlarının ücretleri ile RHD genotiplemesi için girilen SUT kodlarının ücretlerinin kıyaslanması yapılmıştır. RhD (-) gebeye uygulanan maaliyet kalemleri; jinekolojik muayene, yabancı antikor taraması (indirect Coombs), 1 flakon anti-D uygulaması, fetal ultrasonografi (USG) ve fetal orta serebral arter doppler ultrasonografi, (MCA Doppler) uygulamaları olduğu belirlenmiştir (Tablo 1). Ücretlendirmesi belirtilen kodlara göre yapılıp gebe başına maaliyet hesaplanmıştır.

\section{SONUÇLAR VE TARTIŞMA}

Her yıl çok sayıda gebeyi etkileyerek fetal ve neonatal sonuçları olabilen kan uyuşmazlığının, erken teşhis ve tanı ile ortaya çıkabilecek komplikasyonların engellenmesi ve risk altındaki fetüsün invazif olmayan takibine imkân sağlayan yeni yaklaşımların geliştirilmesi, bu alandaki araştırmaların temelini oluşturmaktadır. Günümüzde RhD (-) bir gebenin izlenmesinde uygulanan yaklaşım şu şekildedir. Gebelere 12-16 hafta arası gebe takip sisteminde uygulanan rutin testlere ek olarak serolojik temelli test olan indirekt Coombs testi yapılmaktadır. Uygulanan bu test sonucuna göre tedaviye yön verilmektedir. İndirekt Coombs testi negatif ise, gebeye 28 . haftada anti-D proflaksisi uygulanmaktadır (12). Eğer indirekt Coombs testi pozitif ise, testten elde edilen titreye göre tedaviye yön verilmektedir. Eğer titre, 1/32'den yüksek ise, bebeğin ultrasonografik bulguları değerlendirilmeye alınır. Ultrasonografi sonucuna göre fetal MCA doppler ile bebeğin sistolik basınç değeri fetüsün anemiden etkilenip etkilenilmediğini belirlemede yardımcı olur. Yüksek etkilenme sonucu fetüsün durumuna göre kordosentez önerilir. Ancak, anneye önceki gebeliğinde yapılan anti-D kaynaklı yalancı indirekt Coombs pozitifliğine sebebiyet verebilir. Yalancı pozitiflik durumunda yapılacak olan tüm bu işlemler anne ve fetüs için yıpratıcı olmaktadır. İnvaziv olmayan yöntem ile maternal kandan elde edilen hdfDNA ile gerçek-zamanlı PZR yöntemi kullanarak fetal $R H D$ genotipleme başarısı tarafımızdan ve farklı gruplar tarafından tespit edilmiştir (11,13-15).

Çalışmamızda, maliyet analizi gerçekleştirilmiştir. Halen kullanılan yaklaşım ile yenilikçi bir yaklaşım olan fetal RHD genotipleme sonucu hastaya yansıyan ücretler kıyaslanmıştır. Tablo 1'de RhD (-) gebelere uygulanan ek işlemler ve bunların maliyet analizi gösterilmiştir. Maliyet analizinde SGK'nın Devlet hastaneleri için kullandığı ücretlendirme sistemi olan Sağlık Uygulama Tebliği (SUT 2020) temel alınmıştır. Bu sisteme göre RhD (-) gebeye uygulanılan girişimlerin toplam maliyeti 733,19 TL olarak hesaplanmıştır. RhD (-) gebede fetal RHD durumunun 
belirlenmesi için uygulanan bu yönteminin karşılığı olan 1-5 çift gen analiz işlemin maliyeti ise 210 TL olarak belirlenmiştir.

Tablo 1. Sosyal Güvenlik Kurumu Sağlık Uygulama Tebliği (SUT 2020) Verilerine Göre Test Ücretleri.

\begin{tabular}{lc}
\hline RhD (-) Gebelere Yapılan Ek Testler & Ücretler (も) \\
\hline Jinekolojik Gebe Muayenesi & 50,00 \\
\hline Yabancı Antibody Taraması (Indirect Coombs) & 10,00 \\
\hline 1 Flakon Anti-D & 607,76 \\
\hline USG & 30,25 \\
\hline MCA Doppler & 35,18 \\
\hline Toplam & $\mathbf{7 3 3 , 1 9}$ \\
\hline Fetal $\mathbf{R H D}$ Genotiplemesi & 210,00 \\
\hline 1-5 Çift Baz RT-PCR Uygulaması & $\mathbf{2 1 0 , 0 0}$ \\
\hline Toplam
\end{tabular}

İki farklı yaklaşım arasındaki ücret farkı her bir hasta için 523,19 TL olduğu gösterilmiştir.

Maliyet avantajı açısından öne çıkan gerçek zamanlı PZR yöntemi aynı zamandan uygulanabilirlik olarak da en kolay ve ucuz yöntemlerden bir tanesidir. Son dönemlerde daha hassas olması bakımından tanı alanında kendine hızlı yer edinen yeni nesil dizileme tekniğine göre pratikliği, sarf malzeme alanında ki çeşitliliği, teknik eleman yeterliliği ve uygulanabilirliği yönüyle kısa sürede etkinliğini gösterecektir. Çeşitli ülkelerde, RHD genotiplemesinin maaliyet açısından yapılan değerlendirmelerinde de uygulanılan bu tekniğin maliyetinin çok daha düşük olduğu gösterilmiştir $(16,17)$. Tüm bunlara ek olarak, hastanelerin gereksiz hasta iş yükünü ve invaziv bir girişim olan kordosentez uygulamasıyla oluşabilecek komplikasyon riskini (18) ortadan kaldırmaktadır. Invazif olmayan fetal RhD genotipleme metodu kullanılarak fetüsün RhD durumunun erken belirlenmesi, RhD (-) gebelerde izlenecek gözlem ve müdahale yönetimini önemli ölçüde değiştirilmesine neden olacaktır $(16,19)$. Uygun anti-D profilaksi sağlamak için testin tüm RhD (-) gebeler için sistematik bir şekilde kullanılması, gereksiz uygulanacak işlemle toplamında kişi başına 523,19 TL bir kazanç sağlayacaktır. Maliyetler farklı stratejilerle azaltılabilse de, elde ettiğimiz sonuç bu ve benzeri güncel tanı yaklaşımlarının etkin bir maliyet düşürme stratejisi olduğunu göstermektedir. Yapmış olduğumuz önceki çalışmada, Türkiye'de RhD (-) gebeden doğan RhD (-) bebek oranının \%10 olduğu tespit edildi (11). Bu gebelerin gereksiz anti-D gibi kan ürünü almalarının önüne geçilmesi ve yanlış kullanımın önüne geçilmesini sağlayacaktır.

Sonuç olarak, invazif olmayan fetal $R H D$ genotiplemesi için uygulanan bu yöntem ile tedavi seyri ve başarıyı kolaylaştırma yanında, gebeye gereksiz tedavi uygulama yapılmasını ve oluşan ek maliyeti azaltacağı öngörülmektedir.
Etik Komite Onayı: Bu çalışma icin etik kurul onayı, İstanbul Üniversitesi Tıp Fakültesi Klinik Araştırmalar Etik Kurulu tarafından verilmiştir (08.12.2017/20).

Hakem Değerlendirmesi: Dış bağımsız.

Yazar Katkıları: Çalışma Konsepti/Tasarımı - B.Y., O.Ş., S.S.T.; Veri Toplama - B.Y., O.Ş., S.S.T.; Veri Analizi/Yorumlama - B.Y., O.Ş., S.S.T.; Literatür tarama - B.Y., O.Ş., S.S.T.; Yazım - B.Y., O.Ş., S.S.T.; Eleştirel inceleme - B.Y., O.Ş., S.S.T.

Çıkar Çatışması: Yazarlar çıkar çatışması bildirmemişlerdir.

Finansal Destek: Bu çalışma, İstanbul Üniversitesi Bilimsel Araştırma Projeleri Birimi tarafından desteklenmiştir. Proje No: 29083.

Ethics Committee Approval: Ethics committee approval was received for this study from the Istanbul University Faculty of Medicine Clinical Research Ethics Committee (08.12.2017/20).

Peer-review: Externally peer-reviewed.

Author Contributions: Concept - B.Y., O.Ş., S.S.T.; Data Collection - B.Y., O.Ş., S.S.T.; Data Analysis and/or Interpretation - B.Y., O.Ş., S.S.T.; Literature Search - B.Y., O.Ş., S.S.T.; Writing - B.Y., O.Ş., S.S.T.; Critical Reviews - B.Y., O.Ş., S.S.T.

Conflict of Interest: The authors have no conflict of interest to declare.

Financial Disclosure: This work was supported by the Scientific Research Projects Unit of Istanbul University. Project No: 29083.

\section{KAYNAKLAR}

1. Fasano RM. Hemolytic disease of the fetus and newborn in the molecular era. Seminars in Fetal and Neonatal Medicine 2016; 21(1): 28-34. [CrossRef]

2. Kumar S, Regan F. Management of pregnancies with RhD alloimmunisation. British Medical Journal 2005; 330(7502): 1255-8. [CrossRef]

3. de Haas M, Thurik FF, Koelewijn JM, van der Schoot CE. Haemolytic disease of the fetus and newborn. Vox Sanguinis 2015; 109(2): 99113. [CrossRef]

4. Boggione CT, Luján Brajovich ME, Mattaloni SM, Di Mónaco RA, García Borrás SE, Biondi CS, et al. Genotyping approach for non-invasive foetal RHD detection in an admixed population. Blood Transfus 2017; 15(1): 66-73.

5. Smits-Wintjens VEHJ, Walther FJ, Lopriore E. Rhesus haemolytic disease of the newborn: Postnatal management, associated morbidity and long-term outcome. Semin Fetal Neonatal Med 2008; 13(4): 265-71. [CrossRef]

6. Lo YMD, Bowell PJ, Selinger M, Mackenzie IZ, Chamberlain P, GilImer MDG, et al. Prenatal determination of fetal RhD status by analysis of peripheral blood of rhesus negative mothers. The Lancet 1993; 341 (8853): 1147-8. [CrossRef]

7. Dovč-Drnovšek T, Klemenc P, Toplak N, Blejec T, Bricl I, Rožman P. Reliable determination of fetal RhD status by RHD genotyping from maternal plasma. Transfus Med Hemotherapy 2013; 40(1): 37-43. [CrossRef] 
8. Benachi A, Delahaye S, Leticee N, Jouannic JM, Ville Y, Costa JM. Impact of non-invasive fetal RhD genotyping on management costs of rhesus-D negative patients: Results of a French pilot study. Eur J Obstet Gynecol Reprod Biol 2012; 162(1): 28-32. [CrossRef]

9. González-González C, Garcia-Hoyos M, Trujillo-Tiebas MJ, Lorda-Sanchez I, Rodríguez De Alba M, Infantes F, et al. Application of fetal DNA detection in maternal plasma: A prenatal diagnosis unit experience. In: Journal of Histochemistry and Cytochemistry 2005; 53(3): 307-14. [CrossRef]

10. Yang H, Llewellyn A, Walker R, Harden M, Saramago P, Griffin S, et al. High-throughput, non-invasive prenatal testing for fetal rhesus D status in RhD-negative women: A systematic review and meta-analysis. BMC Medicine 2019; 22(13): 1-172. [CrossRef]

11. Yaşa B, Şahin $O$, Öcüt $E$, Seven $M$, Sözer $S$. Assessment of Fetal Rhesus D and Gender with Cell-Free DNA and Exosomes from Maternal Blood. Reprod Sci 2020; doi: 10.1007/s43032-020-00321-4 [CrossRef]

12. Lambertino JRM, Villegas SMG. Rh Alloimmunization in pregnancy womens, A look to diagnosis and therapeutic approach. Ginecol Obstet Mex 2014; 82(11): 744-54.

13. Clausen FB, Barrett AN, Akkök CA, Armstrong-Fisher S, Bergström $K D$, Boggione $C T$, et al. Noninvasive fetal RHD genotyping to guide targeted anti-D prophylaxis-an external quality assessment workshop. Vox Sang 2019; 114(4): 386-393. [CrossRef]

14. Schmidt LC, Cabral ACV, Faria MA, Monken F, Tarazona-Santos E, Martins ML. Noninvasive fetal RHD genotyping from maternal plasma in an admixed Brazilian population. Genet Mol Res 2014; 13(1): 799-805. [CrossRef]
15. Macher HC, Noguerol $P$, Medrano-Campillo $P$, Garrido-Mírquez MR, Rubio-Calvo A, Carmona-González M, et al. Standardization non-invasive fetal RHD and SRY determination into clinical routine using a new multiplex RT-PCR assay for fetal cell-free DNA in pregnant women plasma: Results in clinical benefits and cost saving. Clin Chim Acta 2012; 413(3-4): 490-4. [CrossRef]

16. Sparks TN, Caughey AB. How should costs and cost-effectiveness be considered in prenatal genetic testing? Seminars in Perinatology 2018; 42(5): 275-282. [CrossRef]

17. Darlington M, Carbonne B, Mailloux A, Brossard Y, Levy-Mozziconacci $A$, Cortey $A$, et al. Effectiveness and costs of non-invasive foetal RHD genotyping in rhesus-D negative mothers: A French multicentric two-arm study of 850 women. BMC Pregnancy Childbirth 2018; 18(1): 496. [CrossRef]

18. Sherwood K, Weimer ET. Characteristics, properties, and potential applications of circulating cell-free dna in clinical diagnostics: a focus on transplantation. Journal of Immunological Methods 2018; 463: 27-38. [CrossRef]

19. Kostenko E, Chantraine F, Vandeweyer K, Schmid M, Lefevre A, Hertz D, et al. Clinical and Economic Impact of Adopting Noninvasive Prenatal Testing as a Primary Screening Method for Fetal Aneuploidies in the General Pregnancy Population. Fetal Diagn Ther 2019; 45(6): 413-423. [CrossRef] 